20

\title{
Новые возможности диагностики колоректального рака с помощью оптической системы детекции клеток на основе диэлектрофореза*
}

\author{
(C) М.В. Кручинина ${ }^{1,4}$, Я.И. Прудникова ${ }^{1}$, А.А. Громов ${ }^{1}$, В.М. Генералов ${ }^{2}$, К.В. Генералов ${ }^{2}$, В.Н. Кручинин ${ }^{3}$, \\ Э.В. Кручинина ${ }^{4}$, Г.В. Шувалов ${ }^{5}$, И.Н. Яковина ${ }^{6}$, Н.А. Баннова ${ }^{6}$, О.В. Минин ${ }^{7}$, И.В. Минин ${ }^{5}$
}

\author{
${ }^{1}$ НИИ терапии и просрилактической медицины - фрилиал „Федеральный исследовательский центр \\ Институт цитологии и генетики Сибирского отделения РАН“, \\ 630089 Новосибирск, Россия \\ ${ }^{2}$ Государственный научный центр вирусологии и биотехнологии „Вектор“ \\ Федеральной службы по надзору в сфере защиты прав потребителей и благополучия человека, \\ 630559 Кольцово, Новосибирск, Россия \\ ${ }^{3}$ Институт фризики полупроводников им. А.В. Ржанова СО РАН, \\ 630090 Новосибирск, Россия \\ ${ }^{4}$ Новосибирский государственный медицинский университет, \\ 630091 Новосибирск, Россия \\ ${ }^{5}$ Сибирский государственный ордена Трудового Красного Знамени НИИ метрологии, \\ 630004 Новосибирск, Россия \\ ${ }^{6}$ Новосибирский государственный технический университет, \\ 630073 Новосибирск, Россия \\ 7 Томский государственный университет, \\ 634050 Томск, Россия \\ e-mail: kruchmargo@yandex.ru
}

Поступила в редакцию 24.12.2018 г.

В окончательной редакции 28.01.2019 г.

Принята к публикации 31.01.2019 г.

\begin{abstract}
С помощью оптической системы детекции клеток на основе метода диэлектрофореза показаны возможности использования электрических и вязкоупругих параметров эритроцитов у пациентов с колоректальным раком (КРР) различных стадий. Наиболее значимыми параметрами для определения пациентов с КРР, а также ранних и поздних стадий, вошедшими в сформированные модели рискометра диагностики заболевания, оказались амплитуда деформации, доля деформированных клеток, обобщенные вязкость, жесткость, положение равновесной частоты, электропроводность. Созданные диагностические „панели“ с высокой диагностической точностью, чувствительностью и специфичностью позволили определить пациентов с КРР (специфичность 0.91, чувствительность 0.96), а также ранние и поздние стадии заболевания (специфичность 0.64 , чувствительность 0.86 )
\end{abstract}

DOI: $10.21883 /$ OS.2019.05.47666.15-19

\section{Введение}

Данные мировой статистики (GLOBOCAN 2018) свидетельствуют о высокой заболеваемости и смертности от колоректального рака (КРР), на который приходится около трети случаев всех злокачественных новообразований [1]. Большая часть используемых в клинической практике методик диагностики КРР трудоемка, дорогостояща, труднодоступна из-за необходимости использования специального оборудования и реактивов, что снижает эффективность скрининга. Среди современных диагностических подходов все большую популярность

\footnotetext{
* The 22nd Annual Conference Saratov Fall Meeting 2018 (SFM'18): VI International Symposium, ,Optics and Biophotonics" and XXII International School for Junior Scientists and Students on Optics, Laser Physics \& Biophotonics, September 24-29, 2018, Saratov, Russia. https://www.sgu.ru/structure/fiz/saratov-fall-meeting/previousconferences/sara
}

приобретает оптический клеточный мониторинг (диэлектрофорез эритроцитов - направленное движение частиц в неоднородном переменном электрическом поле с их оптической детекцией) [2,3]. Метод точен, информативен, малоинвазивен и не требует трудоемкой подготовки образца, его данные хорошо дополняют данные оптических методов анализа, широко используемых в медицине, таких как раман-, ИК спектроскопия, люминесценция $[4,5]$. Целью настоящей работы явилось исследование возможностей оптической системы мониторинга эритроцитов на основе диэлектрофореза [6] для диагностики КРР.

\section{Методы исследований}

Обследованы 100 пациентов с КРР - гистологически подтвержденная аденокарцинома (средний воз- 
раст $63.2 \pm 9.4$ лет (57 мужчин, 43 женщины) и 24 человека группы сравнения, сопоставимых по возрасту и полу (средний возраст $61.7 \pm 7.5$ лет, 14 мужчин, 10 женщин). Определение стадии опухоли толстой кишки уточнено после операции с исследованием патологического образца и с учетом наличия метастазирования в регионарные лимфатические узлы или обнаружения отдаленных метастазов в соответствии с классификацией по TNM. У 45 пациентов выявлены ранние стадии заболевания (I стадия - в 7, II - в 38 случаях), оставшиеся 55 больных оказались с продвинутыми стадиями КРР (III стадия - у 37 человек, IV - у 18). Исследование выполнено с одобрения Комитета биомедицинской этики ФГБУН „НИИ терапии и профилактической медицины“ (29.11.2016, протокол № 123). Все пациенты подписали информированное согласие на участие в исследовании.

Всем пациентам и лицам группы сравнения, кроме общеклинических и инструментальных методов исследования, было проведено исследование электрических и вязкоупругих параметров эритроцитов методом диэлектрофореза с помощью оптической системы детекции клеток (автоматизированной специализированной установки) (рис. 1,a). Подготовка взвесей эритроцитов для проведения исследования описана в [3]. Оценивали индексы агрегации и деструкции, электропроводность, емкость мембран клеток, скорость движения эритроцитов к электродам, положение равновесной частоты, амплитуду деформации, обобщенные показатели вязкости и жесткости, поляризуемость клеток, значения индуцированного дипольного момента [7].

Обобщенный показатель жесткости клетки [N/m] определялся из формулы

$$
c=\frac{\alpha_{\text {кл }} \cdot \varepsilon_{0} \cdot E^{2}}{4 \cdot r \cdot A},
$$

где $a_{\text {кл }}-$ поляризуемость клетки $\left[\mathrm{m}^{3}\right], A-$ амплитуда деформации клетки $[\mathrm{m}]$ (определялась экспериментально), $r$ - радиус клетки [m] (определялся экспериментально); $E$ - напряженность электрического поля $[\mathrm{V} / \mathrm{m}]$ (расчетная величина). Обобщенный показатель вязкости клетки $[\mathrm{Pa} \cdot \mathrm{s}]$ вычислялся в виде

$$
\eta_{\mathrm{c}}=\frac{c \cdot t}{6 \cdot \pi \cdot r \cdot \ln (\Delta x / A)},
$$

$\Delta x$ - мгновенная амплитуда деформации клетки $[\mathrm{m}]$, $t$ - время затухания амплитуды деформации [s]. Мгновенная амплитуда деформации $(\Delta x)$ вычислялась как разность радиусов клетки в деформированном $\left(r_{\max }\right)$ и спокойном $(r)$ состояниях: $\Delta x=r_{\max }-r$.

Для оценки статистической значимости различий трех выборок (выборка $A$ - группа контроля (35 пациентов), выборка $B$ - ранние стадии КРР (64 пациента), выборка $C$ - поздние стадии КРР (59 пациентов) использовали одновременно $U$-критерий Манна-Уитни для попарного сравнения групп и критерии КраскелаУоллеса для одновременного сравнения всех выборок. Для оценки степени корреляции показателей для всех выборок и показателей были рассчитаны коэффициенты корреляции с использованием стандартных средств пакета Statistica 10.0. Для разработки рискометров использовались методы системного и графического анализа. Модели формировались с учетом разных шкал. Оценка результатов проводилась с использованием графического и ROC-анализов.

\section{Методика оптической регистрации}

Для наблюдения диэлектрофореза [7] используют специальные измерительные ячейки, совмещенные со световым микроскопом [8,9]. Методика оптических измерений состояла из следующих основных этапов [8-11]. Измерительная ячейка устанавливается на подвижный стол микроскопа и фиксируется зажимами. Производится фокусировка объектива микроскопа (Микмед 6, увеличение $40-1600^{\times}$) на измерительную ячейку. Далее клеточная суспензия вносится между электродами измерительной камеры и накрывается покровным стеклом. Производится фокусировка микроскопа на клетки (частицы), находящиеся между электродами. После того как клетки придут в состояние покоя, на электроды подается напряжение. С помощью программы видеозахвата производится запись видеофайла поступательного движения частиц между электродами с помощью цифровой видеокамеры „SONY“ с 4.5 mm ПЗС, установленной на микроскопе в качестве фотонасадки, при этом частота оцифровки составляла 25 кадров в секунду. Наблюдение и регистрация ведутся в проходящем свете. Последовательность кадров видеофайла позволяет измерить средний размер частицы, проследить путь, пройденный каждой частицей отдельно, и рассчитать ее скорость. Измерение радиуса частицы производится с помощью эталона сравнения (линейки).

\section{Результаты и обсуждение}

У лиц группы сравнения преобладали дискоциты, которые под действием неоднородного переменного электрического поля с высокой скоростью притягивались к электродам на частотах $1-0.5 \cdot 10^{6} \mathrm{~Hz}$, при этом демонстрировали высокую способность к деформации (рис. $1, b)$. У пациентов с КРР доля дискоцитарных форм достоверно снижалась, клетки образовывали агрегаты различных размеров, которые медленно двигались в направлении электродов. Амплитуда деформации эритроцитов оказалась существенно ниже, чем у здоровых лиц (рис. 1,c).

По мере утяжеления заболевания у больных с КРР отмечено увеличение полиморфизма клеток красной крови - преобладающими в терминальных стадиях оказались шиповидные, сфероцитарные, деструктивные 

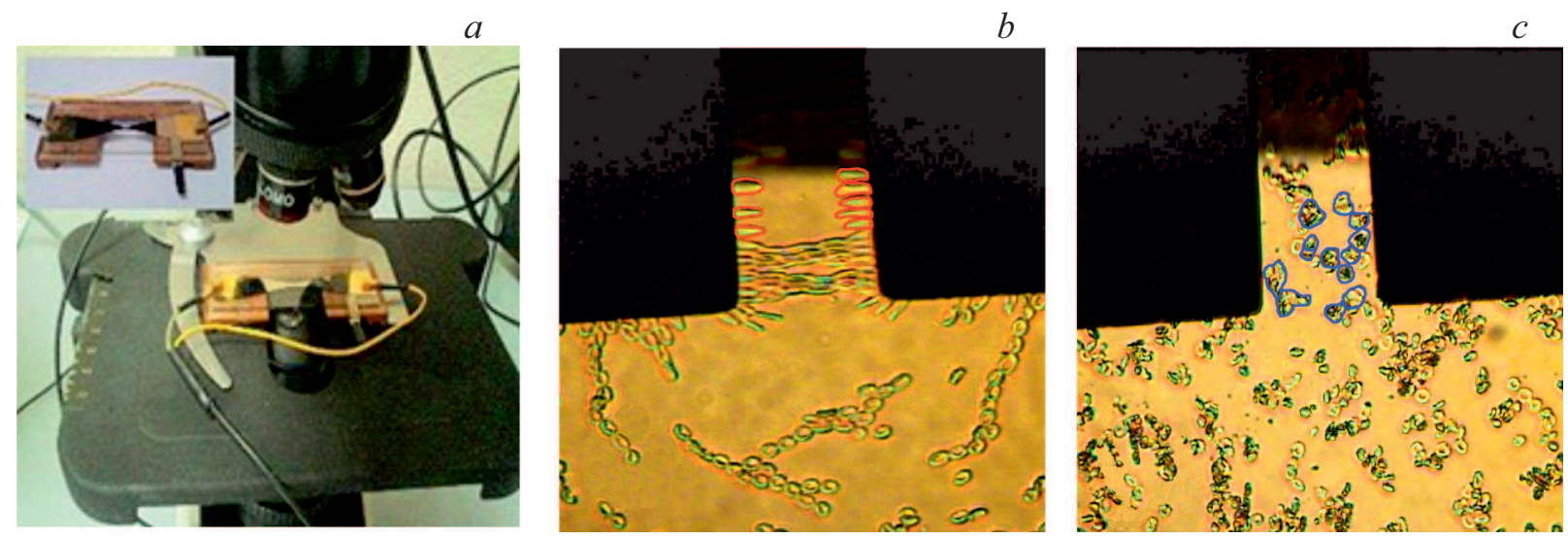

Рис. 1. Оптическая система с ячейкой для ДЭФ-мониторинга эритроцитов. $a-$ внешний вид ячейки; $b, c-$ результаты измерений эритроцитов: $b$ - здоровые обследуемые, $c$ - больные КРР (выделены голубым).

Таблица 1. Электрические и вязкоупругие параметры эритроцитов, вошедшие в сформированные модели рискометра диагностики КРР (различия между исследуемыми группами достоверны $p<0.001-0.05$ )

\begin{tabular}{l|c|c|c|c}
\hline \multicolumn{1}{c|}{ Параметр } & Контроль & Ранние стадии & Поздние стадии & \multicolumn{2}{|c}{ Модель } \\
\hline Амплитуда деформации $\left(\times 10^{-6}\right), \mathrm{m}$ & $8.26 \pm 0.68$ & $6.69 \pm 0.75$ & $5.77 \pm 0.55$ & \\
Доля деформированных клеток, \% & $20.23 \pm 8.1$ & $47.38 \pm 18.68$ & $64.1 \pm 19.54$ & 1 \\
Обобщенная вязкость $\left(\times 10^{-1}\right), \mathrm{Pa} \cdot \mathrm{s}$ & $5.79 \pm 0.73$ & $6.96 \pm 0.47$ & $7.62 \pm 0.35$ & 1 \\
Обобщенная жесткость $\left(\times 10^{-6}\right), \mathrm{N} / \mathrm{m}$ & $6.56 \pm 0.91$ & $8.68 \pm 0.86$ & $9.86 \pm 0.67$ & 1 \\
Равновесная частота, $\mathrm{Hz}$ & $0.49 \pm 0.07$ & $0.83 \pm 1.28$ & $1.8 \pm 1.42$ & 1 \\
Электропроводность $\left(\times 10^{-5}\right), \mathrm{S} / \mathrm{m}$ & $4.99 \pm 0.6$ & $6.62 \pm 1.03$ & $8.29 \pm 1.14$ & 1
\end{tabular}

формы эритроцитов с выраженными явлениями анизо-, пойкилоцитоза и анизохромии $(p<0.05)$, наличие которых затрудняет транспорт кислорода из клеток к тканям и усугубляет гипоксию [12].

Прогрессирование КРР ассоциировано с увеличением уровней обобщенных показателей вязкости, жесткости, значений электропроводности, степени агрегатообразования и гемолиза клеток на всех частотах. В то же время диаметр эритроцитов, амплитуда деформации на частотах $5 \cdot 10^{5}, 10^{6} \mathrm{~Hz}$, поляризуемость клеток на высокой частоте $10^{6} \mathrm{~Hz}$, значение дипольного момента, электрическая емкость мембран эритроцитов снижались $(p<0.001-0.05)$. Выявлено смещение равновесной частоты в высокочастотный диапазон на поздних стадиях КРР $(p<0.01-0.05)$. Установлены обратные корреляции стадии заболевания с амплитудой деформации $(r=-0.611, p=0.02)$, прямые - с обобщенными показателями жесткости $(r=0.562, p=0.014)$, вязкости эритроцитов $(r=0.534, p=0.011)$, электропроводности $(r=0.601, p<0.001)$, положения равновесной частоты $(r=0.628, p<0.001)$.

Наблюдаемые изменения электрических и вязкоупругих параметров эритроцитов, вероятно, связаны как с изменениями структуры их мембран в связи с адсорбцией крупномолекулярных белков, иммуноглобулинов, иммунных комплексов, которые „экранируют“ отрицательный заряд клетки, снижая ее скорость движения к электродам, дипольный момент и снижая емкость мембран [3,12-14]. С другой стороны, изменяется состав, перераспределение в структуре мембраны холестерина, фосфолипидов с нарастанием лизофракций, снижается уровень арахидоновой и повышаются уровни олеиновой, стеариновой жирных кислот, что, возможно, сказывается на обобщенном показателе вязкости, электропроводности [12,13]. Нарастание количества трансформированных клеток под действием опухолевого процесса сопровождается нарушениями ультраструктуры клеток, выражающимися в перераспределении в цитоплазме гемоглобина, усилением образования эндо- и экзовезикул, разрыхлением, уплотнением, деструкцией цитолеммы и т.д., что влияет на обобщенный показатель жесткости и амплитуду деформации [12]. Нарушение формы и снижение деформируемости клеток красной крови, вероятно, возникают в результате разнообразных воздействий на мембрану (гипоксических, иммунных, токсических), имеющих место и при развитии опухолевого процесса [2,12,13]. Сниженная поляризуемость отражает низкую резистентность клеток красной крови, возможно, на фоне угнетающего влияния опухоли на эритропоэз [14-16]. Это приводит к склонности клеток к гемолизу на разных частотах, что усугубляет склонность к агрегации, микроциркуляторным нарушениям [17]. С другой стороны, неопластический рост сопровождается выраженными серологическими перестройками 

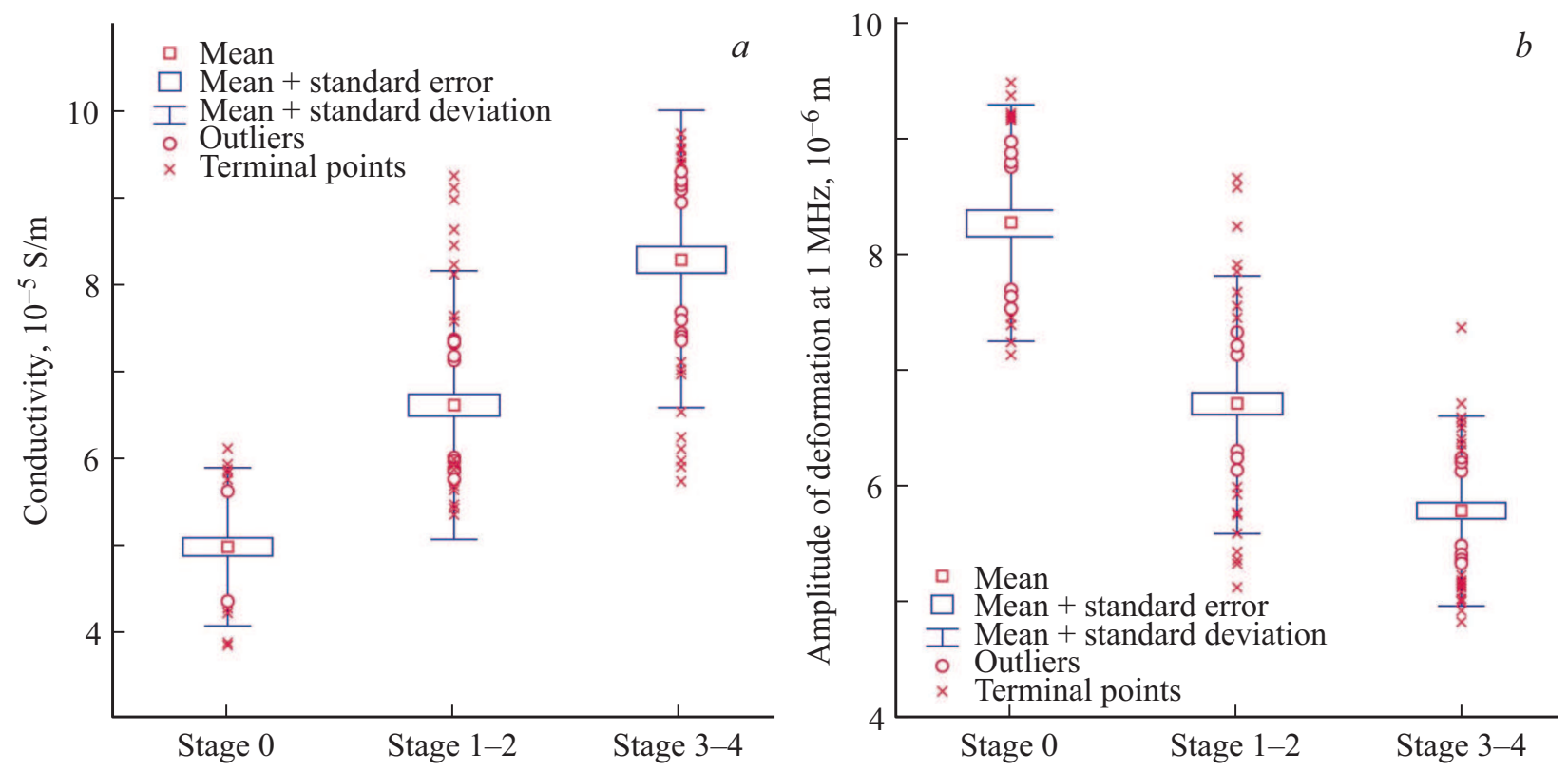

Рис. 2. Тренды средних значений, центров масс, минимальных и максимальных значений выборок для показателей электропроводности $(a)$ и амплитуды деформации $(b)$.

мембран эритроцитов и появлением в крови аутоантител, которые могут быть причиной гемолитических состояний [18]. Полученные результаты легли в основу пилотных ,диагностических панелей“, позволяющих отличать пациентов с КРР от здоровых лиц, а также определять признаки прогрессирования опухолевого процесса [19].

В ходе сравнительного анализа результатов, полученных для всего множества параметров, было выявлено, что некоторые из них имеют ярко выраженный тренд не только средних значений, но и центров масс, а также минимальных и максимальных значений выборок (рис. 2). Это позволило сформировать вариант рискометpa, в который были включены 5 параметров с наличием положительного тренда от минимальных значений для группы контроля (выборка $A$ ) к максимальным значениям, характерным для пациентов с поздними стадиями КРР (выборка $C$ ). Учитывая характер тренда, было предложно использовать линейную комбинацию параметров (табл. 1) с учетом шкалы их измерения. Таким образом, была сформирована модель, позволяющая с высокой степенью диагностической точности (0.95) оценить риск развития КРР.

Второй вариант рискометра был получен на основании графического анализа диаграмм рассеяния (рис. 3), которые позволили выявить ярко выраженные кластеры для исследуемых диагностических групп по ряду параметров. Это явилось основанием для формирования модели другого вида. В рискометр, учитывающий мультипликативный характер выявленных взаимосвязей, были включены 4 параметра. Таким образом, была получена модель с меньшим количеством параметров и

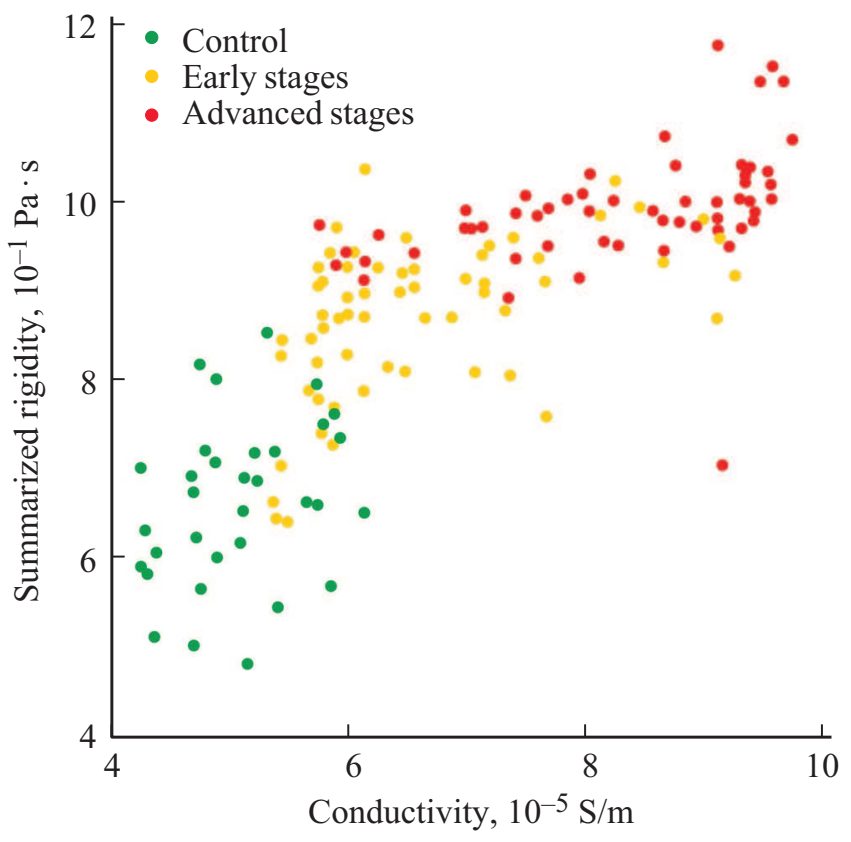

Рис. 3. Графический анализ диаграмм рассеяния для исследуемых диагностических групп по электрическим и вязкоупругим параметрам эритроцитов.

большим диапазоном решаемых диагностических задач: не только оценки риска развития КРР, но и определение степени его прогрессирования.

Разработанные рискометры могут быть использованы для решения двух типов задач: оценка риска развития КРР (у здоровых пациентов) и оценка степени его прогрессирования (переход от ранней стадии к поздней). 

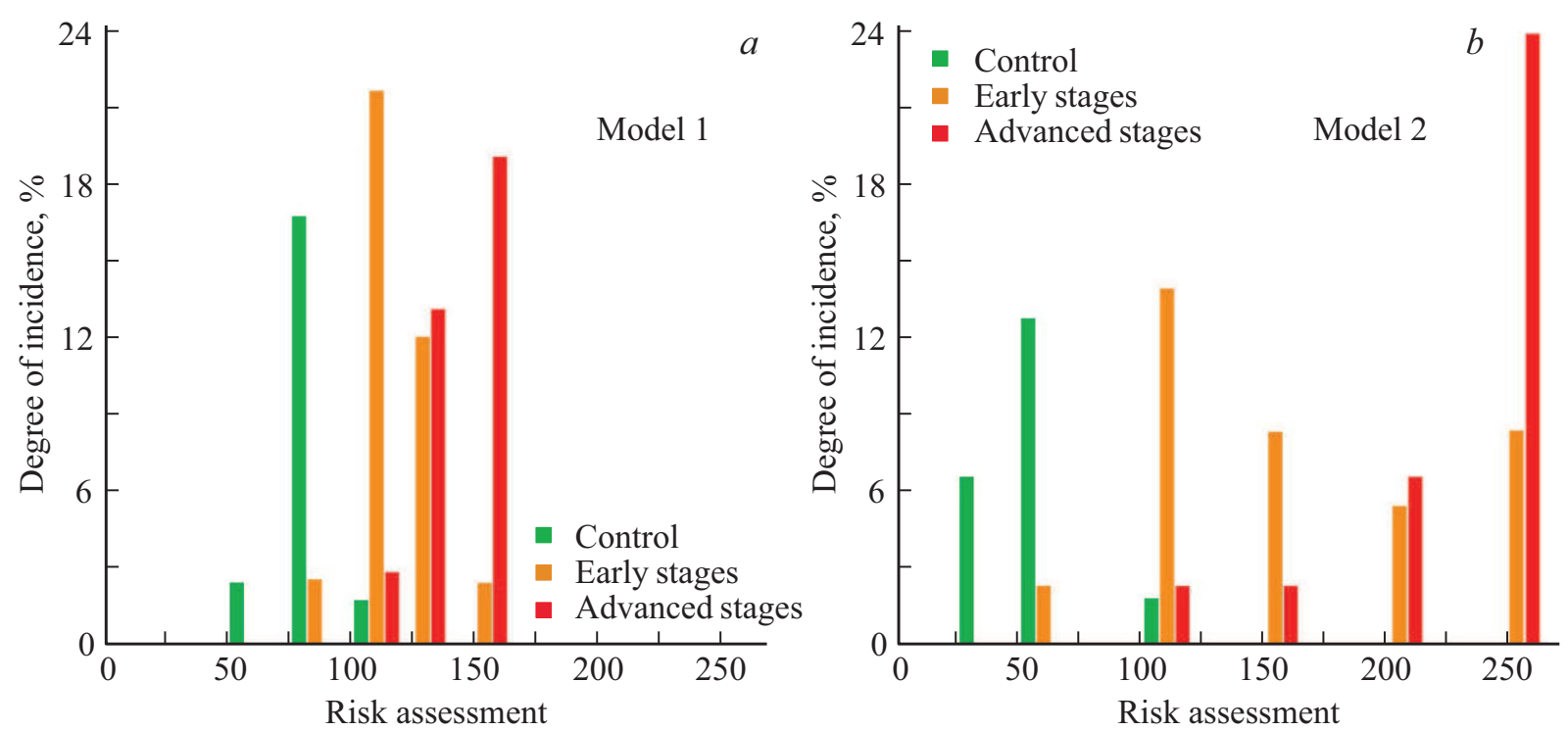

Рис. 4. Результаты применения разработанных рискометров (модели 1 и 2) для трех исследуемых групп пациентов.

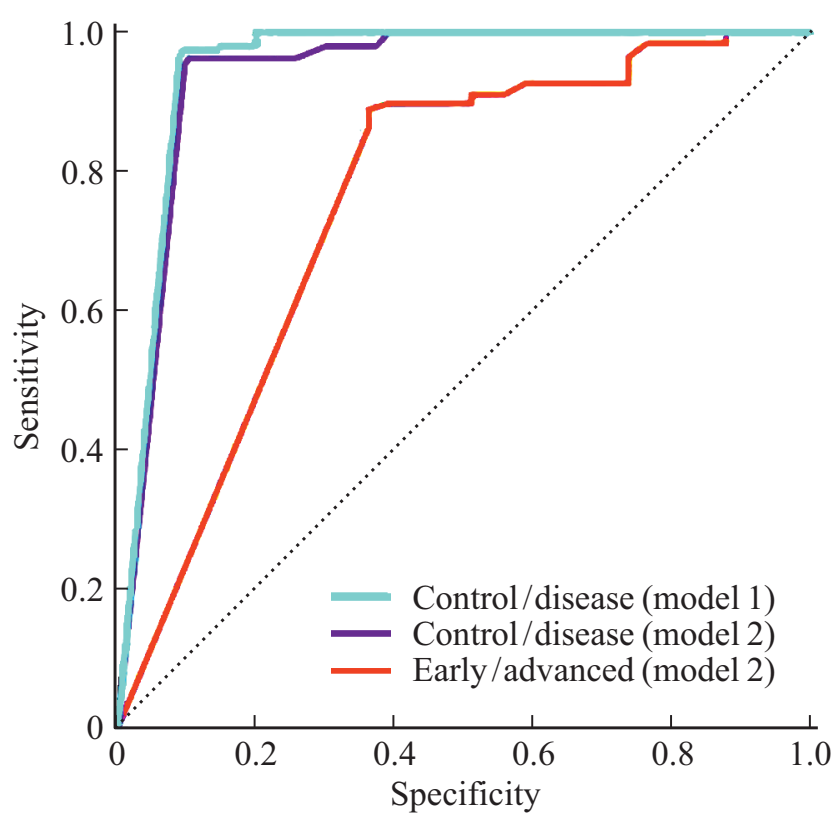

Рис. 5. ROC-анализ исследуемых диагностических панелей для пар группы пациентов (см. текст).

На основании результатов анализа 5 параметров (доля деформированных клеток, обобщенная вязкость, обобщенная жесткость, равновесная частота, электропроводность) для первой модели и 4 параметров (амплитуда деформации, доля деформированных клеток, обобщенная жесткость, электропроводность) для второй модели будет получено значение степени риска в шкале от 0 до 300 условных единиц. Значения в диапазоне от 0 до 100 являются показателем низкого риска. Значение более 100 условных единиц являются индикатором риска наличия КРР у пациента. Вторая модель с высокой
Таблица 2. Показатели диагностической точности представленных моделей для обследуемых групп

\begin{tabular}{c|c|c|c|c|c}
\hline Модель & $\begin{array}{c}\text { Диагности- } \\
\text { ческая } \\
\text { точность }\end{array}$ & $\begin{array}{c}\text { Специ- } \\
\text { фич- } \\
\text { ность }\end{array}$ & $\begin{array}{c}\text { Чув- } \\
\text { стви- } \\
\text { тель- } \\
\text { ность }\end{array}$ & AUC & OR \\
\hline $\begin{array}{c}\text { Модель 1 } \\
\text { (здоровые/ } \\
\text { больные) } \\
\text { Модель 2 } \\
\text { (здоровые/ } \\
\text { больные) } \\
\text { Модель 2 } \\
\text { (ранние/ }\end{array}$ & 0.9557 & 0.9142 & 0.9675 & 0.953 & 317.333 \\
поздние) & 0.7480 & 0.6406 & 0.8644 & 0.762 & 11.3641 \\
\end{tabular}

степенью диагностической точности (0.748) позволяет получить еще одну оценку - степень прогрессирования КРР.

Индикатором прогрессирования является значение рассчитываемого показателя. В диапазоне от 200 условных единиц и выше можно говорить о том, что у пациента с высокой вероятностью может быть диагностирован КРР поздних стадий.

Результаты применения разработанных рискометров для трех исследуемых групп пациентов приведены на рис. 4,5. Характеристики моделей приведены в табл. 2. Для упрощения использования разработанных рискометров в клинической практике планируется разработка калькулятора, позволяющего по результатам введенных значений параметров получать оценку степени риска и его интерпретацию. 


\section{Заключение}

Таким образом, было установлено, что наличие злокачественного опухолевого процесса - КРР - приводит к деполяризации эритроцитов, при этом амплитудночастотные характеристики клетки в неоднородном переменном электрическом поле являются хорошим индикатором физико-химических свойств ее мембраны и цитоплазмы, а также отражают состояние ее биологической активности. Полученные данные по достоверным изменениям параметров красной крови у пациентов с КРР по мере утяжеления заболевания по данным метода диэлектрофореза с использованием оптической системы детекции клеток легли в основу создания пилотных „диагностических панелей“. Высокая диагностическая точность последних позволяет не только выявлять пациентов с КРР, но отличать ранние стадии от поздних. Результаты настоящей работы подтверждают перспективность использования данного подхода в целях диагностики и предполагают продолжение исследования на больших группах пациентов, в том числе при опухолях других локализаций.

\section{Благодарности}

Авторы выражают глубокую благодарность сотрудникам ГБУЗ НСО „НООД“, оказавшим содействие и помощь при обследовании пациентов.

\section{Финансирование работы}

Работа выполнена в рамках темы „Эпидемиологический мониторинг состояния здоровья населения и изучение молекулярно-генетических и молекулярнобиологических механизмов развития распространенных терапевтических заболеваний в Сибири для совершенствования подходов к их диагностике, профилактике и лечению“ ГЗ № 0324- 2018-0001, Рег. № АAАA-А17117112850280-2, опытно-конструкторской работы (шифр „Эритроциты“).

\section{Соблюдение этических стандартов}

Все процедуры, выполненные в исследовании с участием людей, соответствуют этическим стандартам институционального комитета по исследовательской этике и Хельсинкской декларации 1964 г. и ее последующим изменениям или сопоставимым нормам этики. От каждого из включенных в исследование участников было получено информированное добровольное согласие.

\section{Список литературы}

[1] Мейерхардт Джс., Сандерз М. Рак толстой кишки. М.: ООО „Рид Элсивер“, 2009. 186 с.

[2] Генералов В.М., Кручинина М.В., Дурыманов А.Г., Медведев А.А., Сабатов А.С., Сергеев А.Н., Буряк Г.А., Курилович С.А., Громов А.А. Диэлектрофорез в диагностике инфекционных и неинфекционных заболеваний. Новосибирск: Изд-во „ЦЭРИС“, 2011. 172 с.

[3] Генералов В.М., Кручинина М.В., Громов А.А., Шувалов Г.В. Диэлектрофорез в биологии и медицине: учебное пособие. Новосибирск: Изд-во НГТУ, 2017. 179 с.

[4] Elahi N., Kamali M., Baghersad M.H. // Talanta. 2018. V. 184. P. 537. doi 10.1016/j.talanta.2018.02.088

[5] Ogawa M., Takakura H. // Anal. Sci. 2018. V. 34. N 3. P. 273. doi 10.2116/analsci.34.273

[6] Shuvalov G.V., Generalov K.V., Generalov V.M., Kruchinina M.V., Koptev E.S., Minin O.V., Minin I.V. // Russ. Phys. J. 2018. V. 60. P. 1901.

[7] Pohl H. //Appl. Phys. 1951. V. 22. P. 869.

[8] Gimsa J., Marszalek P., Loewe U., Tsong T.Y. // Biophys. J. 1991. V. 60. P. 749.

[9] Gimsa J., Moller T., Schnelle T., Fuhr G. // Biophys. J. 1996. V. 71. P. 495.

[10] Shuvalov G.V., Generalov V.M., Kruchinina M.V., Klekovkin I.V., Minin I.V., Minin O.V. // 12th Int. Conf. on Actual Problems of Electronics Instrument Engineering (APEIE). 2014. P. 153. doi 10. 1109/APEIE.2014.7040862

[11] Шувалов Г.В., Генералов В.М., Кручинина М.В., Минин И.В. // Материалы 7-й Международной научнотехнической конференции „Судометрика-2018“. 15-17 октября 2018. Санкт-Петербург, 2018. С. 70.

[12] Новицкий В.В., Рязанцева Н.В., Степовая Е.А. Физиология и патофизиология эритроцита. Томск: Наука, 2004. $202 \mathrm{c}$.

[13] Новицкий В.В., Степовая Е.А., Гольдберг В.Е., Колосова М.В., Рязанцева Н.В., Корчин В.И. Эритроциты и злокачественные новообразования. Томск: STT, 2000. $288 \mathrm{c}$.

[14] Qiu Y., Cai G., Su M., Chen T., Zheng X., Xu Y., Ni Y., Zhao A., Xu L.X., Cai S., Jia W. // J. Proteome Res. 2009. V. 8. N 10. P. 4844.

[15] Coussens L.M., Werb Z. // Nature. 2002. V. 420. P. 860.

[16] Ballinger A.B., Anggiansah C. // B.M.J. 2007. V. 335. P. 71518.

[17] Rozen P., Young G.P., Levin B., Spann S.J. Colorectal cancer in clinical practice: prevention, early detection and management. London, UK: Taylor and Francis, 2006. 534 p.

[18] Козинеи, Г.И., Макарова В.А. Исследование системы крови в клинической практике. М.: Триада-Х, 1997. 480 с.

[19] Markowitz S.D., Bertagnolli M.M. // N. Engl. J. Med. 2009. V. 361. P. 2449.

\section{Конфликт интересов}

Авторы заявляют, что у них нет конфликта интересов. 